\title{
Reflexive research with mothers and children victims of domestic violence
}

\author{
Lynne Gabriel ${ }^{1, *}$, Hazel James ${ }^{2}$, Jane Cronin-Davis ${ }^{3}$, Zahra Tizro ${ }^{1}$, Tanya Beetham ${ }^{4}$, Ashley Hullock ${ }^{4}$ \\ \& Alex Raynar ${ }^{4}$ \\ ${ }^{1}$ School of Psychological and Social Sciences, York St John University, York, UK \\ ${ }^{2}$ Independent Domestic Abuse Services, York, UK \\ ${ }^{3}$ School of Health Sciences, York St John University, York, UK \\ ${ }^{4}$ Faculty of Health and Life Sciences, York St John University, York, UK \\ *Corresponding author. Email: I.gabriel2@yorksj.ac.uk
}

\begin{abstract}
Aim: This methodological paper outlines a participatory and reflexive research approach in the context of in-depth, small-scale and preliminary qualitative research conversations with a vulnerable population. Developing a participatory and reflexive methodology: The project involved developing in-depth research conversations with three mothers and their children who had experienced domestic violence.

Underpinned by poststructural feminism and relational ethics, a participatory approach to facilitate informal, nondefensive, participant-centred conversational spaces for the women and children was developed. Creating both the relational medium and the dialogical processes through which to engage with the women and children prompted multiple and complex challenges for the research team. Some members of the research team had prior experience of domestic violence, generating implications for ethical and reflexive research practice. Implications for research practice: The study highlights the complexities and challenges of developing a participatory approach with vulnerable populations including the quandaries faced, the importance of critical reflexivity during in-depth qualitative inquiry and the value of utilising a project steering group to support research governance. All members of the research team were emotionally impacted by the research work and the relational engagement with participants. A collaborative, peer-supervisory approach to support the researchers, the research processes - and, ultimately, the participants - was essential. Two case vignettes are included to exemplify researcher experiences
\end{abstract}

This is the peer reviewed version of the following article: Gabriel, L., James, H. , Cronin - Davis, J. , Tizro, Z. , Beetham, T. , Hullock, A. and Raynar, A. (2017), Reflexive research with mothers and children victims of domestic violence. Counselling and Psychotherapy Research, 17: 157-165, which has been published in final form at https://doi.org/10.1002/capr.12117. This article may be used for noncommercial purposes in accordance with Wiley Terms and Conditions for self-archiving. 


\section{Reflexive research with mothers and children}

There is growing interest in research methodologies for qualitative inquiry with children and young people. Whilst evidence exists of methodological innovation through creative and engaged methodologies and methods (Carter \& Ford, 2013; Evang \& Øverlien, 2015; Fargas-Malet, Mcsherry, Larkin, Kelly \& Robinson, 2010; Harris, Jackson, Mayblin, Piekut \& Valentine, 2015; Jackson et al., 2012; Lushey \& Munro, 2014), there is minimal literature which focusses upon the researcher experiences of exploring emotive or contentious human and relational issues (Dickson-Swift, James, Kippen \& Liamputtong, 2009; McCarry, 2012). Similarly, there is a paucity of literature that describes the dilemmas experienced by researchers during an in-depth project with a vulnerable population and the associated decisionmaking processes (Graham, Powell \& Taylor, 2015).

Here, we consider the researcher and research challenges that arose from in-depth research conversations with women and children who had experienced domestic violence (Gabriel et al., 2016). We focus upon the development of a participatory methodology to underpin the research work. Consideration of the research processes involved illustrates the value of critical reflexivity, whilst case vignettes portray key challenges encountered and highlight researcher decision-making.

Literature relevant to reflexive methodologies was sought through academic databases, including Psychinfo and ASSIA, as well as web-based search engines and databases, including Google scholar and Researchgate. Internet searches elicited grey literature, including reports. The term domestic violence and abuse is used, abbreviated to DVA where appropriate, to refer to the wide range of violent, aggressive or abusive incidents that can occur in familial violence.

\section{Methodology}

\section{Developing a participatory methodology}

The philosophical underpinnings of the work reported here are best captured in the values and morals espoused by social constructionism (Gergen, 2009) (recognition of multiple realities), poststructuralist feminism (Baxter, 2008) (questioning taken for granted notions of gender and of relational, group and cultural power dynamics) and narrative approaches (McLeod, 1997; White \& Epston, 1990; Winslade \& Monk, 2007) (storied ways of understanding experiences, perceptions and behaviours). We concur with Baxter (2008) who argues that there is much to gain by adopting a multiperspectival approach to methodological choices, as befits the research task. This reflects our pluralistic leanings.

Narrative approaches value multiplicity and the creation of meaning through interaction. The notion of multiple and open-ended perspectives on any given phenomena sits well with qualitative inquiry and allows for our researcher experiences to coexist alongside those of research participants. Such reflexive methodology, as applied here, incorporates the best of a modernist tradition (some form of realism, critical or historical) and postmodernist insights (regarding the critical role of language in the process of knowledge production). Methodological tensions can be present, alongside recognition that (seemingly) irreconcilable methodologies may coexist within a pluralistic research approach, provided the researchers are clear about their aims, decision- making and reasoned choices. Such a research stance satisfies our feminist-influenced approach, through incorporating the insights of postmodernism and social constructionism, whilst valuing connection with the women's and children's lived experiences (Ramazanoglu \& Holland, 2002) during participant- centred research conversations. 
In aiming for a participant-focused and informed approach, we worked closely with a local DVA agency who provided both gatekeeper and consultative support. We collaborated with their case workers to facilitate conversations with the children and mothers. Three mothers and their children (aged 8-

11) agreed to participate. All mother and child participants had previously engaged in a young person-to-parent aggression and violence programme developed by Respect (a national body providing helplines and services for victims and perpetrators, along with training and consultancy for service providers) and delivered by Independent Domestic Abuse Services (IDAS). IDAS provided gatekeeper access for the study and identified families who were willing to participate in the research. Researcher- gatekeeper synergies positively facilitated the referral and selection, aided by early clarification of roles, relationships and responsibilities (Harris et al., 2015).

Children and young peoples' developmental stage at the time of a research conversation may be a key consideration. There are a number of models of child and youth development, including the Erickson and Erickson (1998) psycho-social model, which suggest that developmental disorders could occur as a result of life experiences. Moreover, psycho-neurological research evidences the biological impact of trauma upon the frontal cortex and considers brain impact of traumatic experiences encountered by children and young people in high-stress contexts such as domestic violence (Arnsten, Raskind, Taylor \& Connor, 2015). Mindful of these, we collaborated with IDAS to develop age- and stage-appropriate formats for the research conversations with children.

Drawing upon a range of arts-based methods (Carter \& Ford, 2013; Fargas-Malet et al., 2010; Katz \& Hamama, 2013; Lushey \& Munro, 2014; Pirskanen, Jokinen, Kallinen, Harju-Veijola \& Rautakorpi, 2015; Swartz, 2011; Yuen, 2004), we developed creative methods through which to engage the children in research conversations, including use of photographs, using video clips, using a secret box, drawing activities and mind-mapping. The settings the children chose for the conversations were school or home. For research conversations with the mothers, we invited them to choose their preferred meeting context. Two chose their home, whilst the third met us in the back- room area of their business. We provided light refreshments for the children, to offer an additional means through which to engage and develop a conversational rapport.

Initially, we had to allay participants' anxieties that we were connected in some way with statutory bodies, to build sufficient relational trust for the research conversations. This was no surprise. The impact of witnessing domestic violence upon children and young people is well attested (Holt, 2013; Katz, 2015; Kennedy, Edmonds, Dann \& Burnett, 2010) and those traumatised by DVA violence may have encountered a number of professionals and organisations, with varying degrees of relevance or success, prior to meeting with a researcher. We engaged with families who had previously participated in therapeutic work and were subsequently enabled to move through trauma into different ways of being and living. Working with the mothers and their children was a humbling experience. Through the medium of the research conversations and by bearing witness to their stories, we felt their sense of despair at the capacity for human violence and destruction and were awed by their strength of spirit in the face of adversity.

\section{Developing ethical approval and consent processes}

The project received ethical approval from the Faculty Research Ethics Committee. All of the researchers involved in facilitating research conversations held enhanced clearance via the UK Disclosure and Barring Service (DBS).Our imperative was to facilitate respectful conversations with mothers and their children in which all of their voices, choices and experiences were heard and prioritised. Key to this process was negotiating informed assent and consent. We engaged with young people who could be deemed to be 'Gillick competent', whilst recognising the need for processes of child assent and parental consent. Gillick competence refers to a young person's capacity to make reasoned choices for themselves (Hunter \& Piersceonik, 2007). We sought to manage the complex terrain of informed assent and consent, aiming to ensure that both the child and the parent understood the implications of engaging in the research. To support this process, age appropriate information sheets were prepared (Tait, Voepel-Lewis \& Malviya, 2007). 
The perils and pitfalls of legal and ethical considerations when seeking consent are reported in the literature, but less evident are detailed analyses of the dilemmas and decision-making involved for researchers (Cater \& Overlien, 2014; Dockett, Einarsdottir \& Perry, 2009; Graham et al., 2015; Houghton, 2015) and the relational interactions that frame those processes. In forming a process-focused and dialogical approach to ethics for in-depth qualitative research, participant subjectivity was prioritised and objectivity intentionally dismissed (Bakhtin, 1981; Gergen, 2009).

In our navigation of complex and competing ethical and legal imperatives, we remained focused upon participant's voices and needs (Jones \& Stanley, 2008). An example occurred when one of the children withdrew their consent to continue engagement with the research. With a small participant group, the withdrawal of one child impacts significantly. However, despite the impact for the project, the right of that child to withdraw was an ethical imperative reflecting authentic engagement with participants and respect for their individual right to withdraw (Lewis, 2010).

Gaining ethical approval for research with vulnerable populations can be daunting. Most ethics committees take a risks-based approach (Scott \& Fonsesca, 2010), and the process can be complicated where research collaborators are involved in signposting participants (Hutchfield \& Coren, 2011). Our research team engaged in an iterative process with the ethics committee, culminating in full ethical approval. Our capacity for critical reflexivity was essential to the success of this part of the research process (Punch, 2002).

\section{Developing ethical and critically reflexive research practice}

We use the concept critical reflexivity to describe a process of iteratively engaging with people, processes, phenomena, feelings and perceptions (Alvesson \& Skoldberg, 2000, 2009). We sought to provide a critical yet compassionate and reflexive focus on both participant and researcher well-being, as well as create reflexive 'scaffolding' processes to support the research work. Gergen (2009) aptly describes critical reflexivity as a process of questioning taken for granted assumptions and of allowing constant comparison from multiple standpoints. Our engagement with mothers and children involved progressive iterations of meaning-making in relation to research decisions, actions and outcomes, alongside recognition of the impact of our personal histories upon these processes.

Where researchers have experience of the phenomena they are exploring, reflexivity becomes essential to facilitate the research processes and decisions. Some members of the research team had prior experiences of familial or interpersonal violence. Two had experienced their own domestic abuse and violence in early years and as young adults; both had subsequently moved into therapy and helping work, working with family members traumatised by domestic violence. Another had worked in secure settings with victims and perpetrators of violence. A further member had researched sexual and intimate partner violence in diverse cultural settings. For the research assistants involved in the research conversations, transcription and analytical phases elicited emotional responses to the work. 
The participants' stories were brutal and impacted on the researchers. We used regular peer supervision conversations to help manage our responses to the highly emotive content of participants' stories. The brutalising yet compelling stories left their mark. Supportive conversations helped to foster researcher resilience and the capacity to sustain self through the murky and potentially chaotic research terrain of abuse and human violence. The presence of a collaborative, informed and supportive research partner was an important influence. IDAS's ongoing support for participants was a significant feature, and the teamwere assured of their authentic and engaged care for the mothers and children.

Participant anonymity in small-scale projects such as ours is paramount. Whilst we might want to transparently identify researchers or case workers, in so doing we can inadvertently include information that could lead to identifying a participant's identity. It is a real dilemma. The more we highlight researcher identity and processes, and the more we unpack our decision-making to bring a paper to life, the more we put participants at risk of being identified. Managing these tensions was challenging. Given the small sample, local research context and highly sensitive nature of the research topic, we chose not to show researcher or case worker names.

The project steering group played a central role in supporting our research processes and ethical governance. The group included members of the research team, faculty representatives and external colleagues from a number of organisations providing domestic violence services. Whilst we did not have child protection officers directly involved in the project or steering group, the team was well networked with child and adult protection services and the research partner, IDAS, worked directly with statutory bodies including police and adult/child safeguarding agencies.

In the following sections, two case vignettes exemplify the challenges and iterative processes we typically engaged with during the course of the project, through the lens of critical reflexivity. One case considers a dilemma associated with the context of the research conversation, whilst the other reviews the analytical and personal challenges encountered when exploring emotive or personally significant topics.

\section{The research process and impact - two case vignettes}

\section{Case vignette 1: the emotional impact of research work}

One of the project researchers conducted the research conversations with children. All of the research team encountered highly emotional responses to the children's stories. The experience of engaging in research conversations with one of the participants, George (pseudonym), elicited an emotional response in relation to the researcher's reaction to engaging with him. The researcher had met with him across two preliminary meetings and two research conversations. George's story was heart-rending and his relational presentation elicited strong protective instincts in the researcher. George's autonomy and capacity to decide how and when he worked with the researcher played a key part in their engagement, enabling development of a trusting rapport. The researcher's own experience of domestic abuse influenced their reaction to George's story and elicited a desire to help, alongside the knowledge that 'helping' was not their role in the research context. They were struck by the cruel nature of George's story, yet equally impacted by his strength of character and evident resilience in the face of significant and sustained trauma.

The researcher was congruent and transparent about the impact of meeting and working with George and was able to process this with a colleague in the project team. The researcher was impressed by George's resilience and spirit. They had not spoken much about their own experiences as a child. Engaging with George, bearing witness to his story and experiencing his resilience, positively influenced them to start talking about their own past 
Researchers transcribing the research also experienced reactions to the young persons' stories. One researcher found listening to the transcripts particularly upsetting and spoke of crying as she transcribed them. The other spoke about becoming hypervigilant to potential aggression or violence. This reflects Etherington's (2007) experience of working with vulnerable participants and realisation of the impact upon researchers. As Etherington (2007) notes, it '.. .may not be the material itself that creates stress, but, rather, feeling alone with it' (p89; original emphasis).

Although George had come to the attention of IDAS as a young perpetrator of violence and aggression, he had also been victimised by a brutalising and violent father and experienced deeply traumatic events. He had been vilified by his non-abusive parent as a 'demon', yet George displayed symptoms of post-traumatic stress. George's story elicited both despair and anger in the research team; he was not a bald statistic in the media, he was a young person who had been subjected to violence and abuse. Whilst that might not condone his behaviour towards his non-abusing parent, it raises important points about the complexity of DVA situations, which we aimed to be mindful of throughout the research.

\section{Case vignette 2: a research conversation in an unpredictable context}

Two members of the project team facilitated a research conversation in an unpredictable context, a setting that initially felt as if it would not be conducive to a productive research conversation. Typically research conversations take place in a mutually convenient, private space; one which is free from distraction and disturbances. They are a snapshot of a given moment in time and entirely dependent on the relationship with research participants. When meeting one of the research participants for the project in her own business, it became evident that the mother felt unprepared for her conversation with the researchers. The researchers had been under the impression that the mother would take them to her 'office' or a private space for her scheduled research meeting. Unfortunately this was not the case. The location had been suggested to the mother by a case worker, and both researchers realised immediately that the confidentiality and integrity of the research conversations could be compromised by the venue.

The dilemma unfolded as to whether we should continue with the meeting, postpone or abandon it. The mother seemed unsure what to do for the best, and this culminated in a discussion between the researchers and the participants about how the meeting could proceed. The researchers were cognizant of the potential, perceived power differential which might be experienced by the mother. Such power differences have the potency and potential to distort the research conversation. According to Cantelbury (2005), a high level of personal commitment is required for research interviews and researchers need to ensure participants feel comfortable, valued and appreciated. Arguably, power disparities exist in many research scenarios, with participants having little control over the questions, research directions, modes of inquiry or the knowledge that is produced (Scantelbury, ibid). Bordeau (2000) refers to levels of power within research relationships as ranging from high to low. In this project, the researchers wanted those present to have equal power and facilitated a conversation, whereby the choice about how to proceed and where to conduct the research meeting was negotiated. Despite the researchers' internal reservations that the meeting should proceed, they felt unable to voice this for fear of damaging the researcher-participant relationship. However, the participant indicated that she wished the research conversation to go ahead and the only 'space' available to her was the fire exit behind the shop. The participant decided they wanted the conversation to go ahead and it proceeded without interruption from people in the shop. 
During the research conversation, she had a trusted person running the shop and this may have influenced both her decision on context and her willingness to contribute to the research. The participant responded to the questions with detailed information about her personal experiences, those of her son and the shame and guilt that she felt. Recognising that the setting was not ideal, the researchers sought to overcome the fact that this was not the best and most conducive environment for a research conversation. Moreover, the lead researcher conducted the meeting as best she could, was careful about remaining neutral to the surroundings, and aimed to build a conversational partnership (Rubin \& Rubin, 1995).

The cases shown here illuminate relational dilemmas and ethical decision-making in action (Gabriel, 2016). In case 1, through reflection with another team member, the researcher was able to process their reactions to engaging with George. Arguably, central to work within the counselling professions is the capacity to proffer humanitarian values and ethical principles not only to our clients - in this case, our research participants - but also to ourselves. This fundamental principle can be appropriately embraced and embedded in our qualitative research designs, whilst recognising the inevitable challenges to this in the day to day minutia of research work.

All of the research team acknowledged emotional reactions to George's story, recognising revulsion and concern at the abuse that the boy had endured. For some time, a sense of despair prevailed. A key dimension was the presence of others in the research team, who were able to support emotional reactions to participants' stories and to challenge any bias or 'blind spots' when engaging with data analyses.

In case 2, the lead researcher exemplifies a dialogical and collaborative stance, as she attempts to work with the participant to negotiate and agree the context for the research conversation. Both cases highlight the importance of being able to access one's reflexive capacities, within an overall framework that prompts relational reasoning, thoughtful decision- making and courageous resilience to take action in what can be experienced as unsettling or anxiety- invoking research contexts. As a research team, we had a number of conversations with regard to where best to conduct the research conversations with mothers and children. We let our participants make that decision as we wanted them to feel at ease, whilst recognising the challenges of varying contexts. On one occasion, the mother was concerned that her eldest son (age 13) did not want us there, fearing that we were associated with the police or social services. Only after we introduced ourselves as academics and researchers did he begin to feel at ease with us being there. All research contexts have their limitations and best practice is to make sure both participants and researchers feel safe.

As qualitative researchers, we aimed to be immersed and reflexive participants, fully engaged in the research processes and outcomes (Ellis, Adams \& Bochner, 2010) reflecting a participatory approach that equally values contributor and researcher involvement (Birch \& Miller, 2000; Dickson-Swift et al., 2009). Arguably, all deep qualitative exploration and analytical work transforms researchers into co- participants and elicits a co-created project. 


\section{Discussion}

In-depth participatory inquiry with vulnerable populations is not for the faint-hearted. The cases outlined above convey some of the lived challenges and experiences, for both researchers and participants, when engaging in research conversations with children and mothers who have been victims of domestic violence and abuse. For some of us in the team, the research work elicited disturbing memories, alongside contemporaneous psychological reactions to hearing participants' traumatic accounts. For participants, it restimulated thoughts and reactions in response to previous abuse and trauma. Equally, the research fostered deeper valuing of self, along with further understanding of what prompts inhumanity in the face of vulnerability. This was the case for both researchers and participants and exemplified by one mother who valued the opportunity to talk about her experiences and expressed her keenness to see people better informed aboutDVA.

A researcher's history, whatever that entails, will form part of the research process and data analyses. A poststructuralist qualitative research approach recognises that researcher knowledge and preconceptions affect the application of agency (Luca, 2009). We recognise that tensions exist between feminist, poststructuralist and social constructionist positions on research, yet believe that these can coexist within a pluralistic research framework. We do not attempt to 'bracket' our history, experiences and personal or professional interests, but rather, to embody critical reflexivity, whereby our biographical impact becomes part of the multiple dimensions of the research process. It is a case of being hyperaware of our inner wounded healer (Sedgewick, 1994) and our impact upon others and our environment. This is especially significant for practitioner-researchers engaging with vulnerable populations. Indeed, counselling and mental health professionals who engage in research can positively and appropriately draw upon their practitioner knowledge and skills to inform research work (Gabriel, 2009). Mindful of how in-depth qualitative inquiry in the social and health sciences can be negatively perceived as indulgent and unscientific, we advocate the importance of upholding relational and reflexive approaches that witness and narrate participants' stories. In this respect, we resonate with an autoethnographic approach, with our researcher vulnerability and quandaries evident for both participants and readers (Ellis et al., 2010; Tamas, 2009). We were also mindful of the influence of the rights agenda, with children formerly seen as passive recipients or victims now increasingly regarded as active agents who can demonstrate autonomy and are able to reflexively engage in research and with researchers (Fargas-Malet et al., 2010; Graham et al., 2015; Harris et al., 2015).

The necessity to establish trustworthiness in in-depth research work means engaging transparently and authentically. Through adopting an internal dialogue, using a critical, reflexive approach, which Luca (2009), p.6 refers to as 'circling of consciousness', it is possible to examine our agency throughout the research process. Selfawareness is critical in this research process. As a research group with backgrounds in counselling, psychology and mental health, we recognised that researcher self-awareness can be learned and enhanced for ethical and effective research (Cunliffe, 2004). In managing our researcher tensions and difficulties, we did not objectify our research participants or processes, but aimed for a stance of compassionate distance (Gabriel, 2005, 2016).

Qualitative researchers reflexively interact with participants, as well as interpret their world. Establishing trust with participants is more likely to result in greater quality to the stories told. Reliability and validity of data analyses and findings is essential for the research to have credibility in professional circles. Peer review supported the data analyses, and themes were identified, shared and reviewed within the team, to support and triangulate analytical work. There is no 'one size fits all' approach to managing the sometimes chaotic landscape of in-depth qualitative analyses, but an openness to challenge and be challenged helps; essentially epitomising a transparent and trustworthy process, in which there are no lone researchers and through which any concerns associated with data analyses can be processed.

However, there are limitations to the research approach discussed here. We cannot assume the experiences of the research team would be replicated elsewhere; nor can we expect that other researchers would value a team approach, or seek the support or contributions of a steering group to foster critical reflexivity during the research design and processes. That said, the decisions and processes articulated here could usefully inform other researchers. Significantly, the value of working collaboratively in a multidisciplinary research team cannot be underestimated, not least in relation to the benefits arising from accessible support and research consultancy, as well as assistance with holding compassion for self and others in the face of researching sensitive research 
topics. Conceivably, research consultation or supervision empowers us to make ethical research process and practice decisions in the flux and course of our lived research experiences. That process will place participants at its core.

\section{Implications for research practice}

The methodological issues outlined here convey several key implications for practice. Particularly noteworthy are (i) the significance of transparently working through quandaries when making research decisions; (ii) the centrality of critical reflexivity for supporting research and researcher processes, dilemmas and ethical decisionmaking; (iii) the importance of peer supervision to mitigate any researcher sense of isolation or loneliness; and (iv) the value of engaging a project steeringgroup.

We agree with Tamas (2009) that too many reports of qualitative inquiry, with their inevitable 'messiness', are sanitised. Adopting a critically reflexive approach to in-depth qualitative inquiry, as outlined here, can foster researcher and research design resilience and facilitate an embodied and relational approach to engaging with projects and participants. Emotive research topics require researcher/research process 'scaffolding' which can be developed through a dialogical and critically reflexive approach. By 'scaffolding', we mean putting in place supportive, enabling and protective tactics and approaches. As a minimum, all researchers should research within supervised research practice, to ethically scaffold their work and research relationships and to support them in what could be a lonely endeavour.

\section{Conclusion}

We need more researchers and research publications to authentically and transparently narrate the quandaries and difficult decision-making processes encountered in qualitative inquiry. With increasing focus on child and youth mental health, as well as on citizen mental health more generally, it is timely to debate the challenges of developing ethical research dialogues on sensitive issues if we want to ensure we hear the voices of the vulnerable and disseminate their stories.

\section{Acknowledgements}

We would like to thank York St John's Faculty of Health and Life Sciences, who provided strategic investment funding for the youth-to-parent aggression project. Thank you also to IDAS and to the mothers and children whogenerouslycontributed tothestudy. 


\section{References}

Alveson, M., \& Skoldberg, K. (2000). Reflexive methodology: Interpretation and research. London: Sage.

Alvesson, M., \& Skoldberg, K. (2009). Reflexive methodology: New vistas for qualitative research, 2nd edn. London: Sage.

Arnsten, A. F. T., Raskind, M. A., Taylor, F. B., \& Connor,

D. E. (2015). the effects of stress exposure on prefrontal cortex: Translating basic research into successful treatments for post-traumatic stress disorder. Neurobiology of Stress, 1, 89-99.

Bakhtin M. M. (1981). The dialogic imagination. Austin, TX: University of Texas.

Baxter J. (2008). Feminist post-structuralist discourse analysis - a new theoretical and methodological approach? In K. Harrington, L. Litosseliti, H. Sauntson, \& J. Sunderland (Eds.), Gender and language research methodololgies (pp. 243255). London, UK: Palgrave- Macmillan.

Birch, M., \& Miller, T. (2000). Inviting intimacy: The interview as a therapeutic opportunity. International Journal of Social Research Methodology, vol 3(3):189- 202.

Bordeau B. (2000) Dual relationships in qualitative research. The Qualitative Report. 4: 3-4.

Carter, B., \& Ford, K. (2013). Researching children's health experiences: The place for participatory, child- centered, artsbased approaches. Research in Nursing and Health, 36, 95-107.

Cater, A., \& Overlien, C. (2014). Children exposed to domestic violence: A discussion about researcher ethics and researchers' responsibilities. Nordic Social Work Research, 4, 67-79.

Cunliffe A. L. (2004). On becoming a critically reflexive practitioner. JournalofManagementEducation 28:407- 426.

Dickson-Swift, V., James, E. L., Kippen, S., \& Liamputtong, P. (2009). Researching sensitive topics: Qualitative research as emotion work. Qualitative

Research, 9, 61-79.

Dockett, S., Einarsdottir, J., \& Perry, B. (2009).

Researching with children: Ethical tensions. Journal of Early Childhood Research, 7, 283-298.

Ellis C., Adams T. E., \& Bochner A. P. (2010).

Autoethnography: An overview [40 paragraphs]. Forum Qualitative Sozialforschung/Forum: Qualitative Social Research, 12(1), Article 10.

Erickson, E., \& Erickson, J. (1998). The life cycle completed.

London: Norton.

Etherington, K. (2007). Working with traumatic stories: From transcriber to witness. International Journal of Social Research Methodology, 10, 85-97.

Evang, A., \& Øverlien, C. (2015). 'If you look, you have to leave’: Young children regulating research interviews about experiences of domestic violence. Journal of Early

Childhood Research, 13, 113-125.

Fargas-Malet, M., Mcsherry, D., Larkin, E., Kelly, G., \& Robinson, C. (2010). Research with children: Methodological issues and innovative techniques. Journal of Early Childhood Research, 8, 175-192. 
Gabriel, L. (2005). Speaking the unspeakable: The ethics of dual relationships in counselling and psychotherapy. London: Routledge.

Gabriel, L. (2009). Exploring the researcher-contributor alliance. In L. Gabriel, \& R. Casemore (Eds.), Relational ethics in practice: Narratives from counselling and psychotherapy, (pp. 147-157). London: Routledge.

Gabriel L. (2016) Ethical decision-making for the counselling professions. Lutterworth: BACP.

Gabriel L., Tizro Z., James H., Cronin-Davis J., Beetham T., Corbally A., Lopez-Moreno E., \& Hill S. (2016). Give me some space: Exploring young person-to-parent aggression and violence. Journal of Family Violence. (in peer review).

Gergen, K. (2009). An Introduction to social construction.

London: Sage.

Graham A., Powell M. A., \& Taylor N. (2015). Ethical research involving children: Encouraging reflexive engagement in research with children and young people. Children and Society 29:331-343.

Harris, C., Jackson, L., Mayblin, L., Piekut, A., \& Valentine, G. (2015). 'Big Brother welcomes you’: Exploring innovative methods for research with children and young people outside of the home and school environments. Qualitative Research, 15, 583599.

Holt, A. (2013). Adolescent-to-parent abuse: Current understandings in research, policy and practice. Bristol: The Policy Press.

Houghton, C. (2015). Young people’s perspectives on participatory ethics: Agency, power and impact in domestic abuse research and policy-making. Child Abuse

Review, 24, 235-248.

Hunter D., \& Piersceonik B. K. (2007). Children, Gillick competency and consent for involvement in research. Journal of Medical Ethics 33:659-662.

Hutchfield, J., \& Coren, E. (2011). The child's voice in service evaluation: Ethical and methodological issues. Child Abuse Review, 20,173-186.

Jackson, L. A., Witt, E. A., Games, A. I., Fitzgerald, H. E., Eye, A., \& Zhao, Y. (2012). Information technology use and creativity: Findings from the children and technology project. Computers in Human Behavior, 28, 370-376.

Jones, M., \& Stanley, G. (2008). Children’s lost voices: Ethical issues in relation to undertaking collaborative, practicebased projects involving schools and the wider community. Educational Action Research, 16, 31-41.

Katz, E. (2015). Domestic violence, children's agency and mother-child relationships: Towards a more advanced model. Children and Society, 29, 69-79.

Katz, C., \& Hamama, L. (2013). “Draw me everything that happened to you”: Exploring children’s drawings of 
sexual abuse. Children and Youth Services Review, 35, 877- 882.

Kennedy, T., Edmonds, W., Dann, K., \& Burnett, K. (2010). The clinical and adaptive features of young offenders with histories of child-parent violence. Journal

of Family Violence, 25, 509-520.

Lewis, A. (2010). Silence in the context of 'child voice'. Children and Society, 24, 14-23.

Luca M. (2009) Embodied Research and Grounded Theory.UK: University of Wales.

Lushey C. J., \& Munro E. R. (2014). Participatory peer research methodology: An effective method for obtaining young people’s perspectives on transitions from care to adulthood? Qualitative Social Work, 14(4), 522-537.

McCarry, M. (2012). Who benefits? A critical reflection of children and young people’s participation in sensitive research. International Journal of Social Research

Methodology, 15(1), 55-68.

McLeod, J. (1997). Narrative and psychotherapy. London: Sage.

Pirskanen, H., Jokinen, K., Kallinen, K., Harju-Veijola, M., \& Rautakorpi, S. (2015). Researching children’s multiple family relations: Social network maps and life- lines as methods. Qualitative Sociology Review, 11(1), 50- 69.

Punch, S. (2002). Research with children. The same or different from research with adults? Childhood, 9, 321- 341.

Ramazanoglu, C., \& Holland, J. (2002). Feminist methodology: Challenges and choices. London: Sage.

Rubin, H. J., \& Rubin, I. (1995). Qualitative interviewing: The art of hearing. London: Sage.

Scantelbury K. (2005). Maintaining Ethical and Professional Relationships in Large Qualitative Studies: A Quixotic Ideal? Art 3(39).

Scott, C. L., \& Fonsesca, L. (2010). Overstepping the mark: Ethics procedures, risky research and education researchers. International Journal of Research \& Method in Education, 33, 287-300.

Sedgewick, D. (1994). The wounded healer: Counter- transference from a Jungian Perspective. London: Routledge.

Swartz, S. (2011). 'Going deep'and 'giving back': Strategies for exceeding ethical expectations when researching amongst vulnerable youth. Qualitative Research, 11, 47-68.

Tait, A. R., Voepel-Lewis, T., \& Malviya, S. (2007).

Presenting research information to children: A tale 
L. Gabriatralethods. Anesthesia and Analgesia, 105, 358-364.

Tamas S. (2009). Writing and righting trauma:

Troubling the autoethnographic voice [24 paragraphs]. Forum Qualitative Sozialforschung/Forum: Qualitative Social Research, 10(1), 22.

White, M., \& Epston, D. (1990). Narrative means to therapeutic ends. London: Norton.

Winslade, J., \& Monk, G. (2007). Narrative counselling in schools: Powerful and brief. London: Corwin.

Yuen, F. C. (2004). "It was fun.. I liked drawing my thoughts”: Using drawings as a part of the focus group process with children. Journal of Leisure Research, 36, 461-482. 
